\title{
AN INCLUSIVE INDIAN NATIONAL THERAPY
}

\author{
P.Velayudha Panicker \\ Former Professor of Pharmacognosy, College of Pharmaceutical Sciences, Medical College, Thiruvananthapuram, Kerala, India,695011.
}

Article history: Received: 20 February 2013, Accepted: 12 March 2014, Available online: 3 April 2014

\begin{abstract}
A road map to bring Patient-oriented clinical results of ethnic traditional processes \& techniques through a single window of modern hospitals for documentation and accountability where 'clinical Pharmacognosist' has a link role between MCI and AYUSH to evolve an "inclusive health care policy" for the nation.
\end{abstract}

Key words: clinical results of ethnic traditional processes, documentation, Clinical Pharmacognosist, MCI, AYUSH, PCI, CCIM, JAMA, NCHRH, AICTE

We have two tier system of therapy operative in India, one being modern allopathic system and the other representing several diverse ethnic practices scattered across the country which owe their supportive credibility to the Ayurveda, Sidha, Yoga, Naturopathy or Unani with subsequently introduced Homeopathy - a system originated in Germany. The ethnic multiplicity of Indian social fabric in relation to traditional variation in practices have been discerned from a migratory school of 'Caraka' (Charaka is written as Caraka in Devanagari script) (Chara denotes movement) through ages to give Ayurveda adapted for different regions. The beauty of this diversity in practices has been the rationale for the sustainability of these processes and techniques in this country without stumbling to piracy over a considerable period of time. The question that is posed today is whether the Indian traditional therapy is to be called an alternative therapy or a parallel complementary system? In case of complementary system, is there a need to make it inclusive and productive under the same roof to bring out the clinical results through a single window to make it nationally accountable? - A road map for an inclusive growth of Indian National Therapy.

AYUSH was recreated by Government of India in November, 2003 to preserve Ayurveda, Yoga, Naturopathy, Unani, Sidha \& Homeopathy in its conceptual mode of treatment in par with IMC an organization to control the standard of modern medicine.

For Correspondence: pvp@asianetindia.com

Contact: pvpanicker.com@gmail.com

Hygeia.J.D.Med. Vol.6 (1), April 2014 () 2014, all rights reserved.

Hygeia journal for drugs and medicines, 2229 3590, 09756221

D.O.I: $10.15254 /$ H.J.D.Med.6.2014.129 
The Pharmacy Council of India right now perform as an auxiliary function of IMC and gone ahead while designing Pharm.D course to engage Pharmacists in direct Patient care of modern super-specialty hospitals on one side while in collaboration with AICTE prepare industrially oriented Pharmacists to work as manufacturing technologists.

In context of undergraduate level of Pharmacy, Pharmacognosy syllabus designed by AICTE includes certain basic induction to Indian holistic systems of medicine approved as all India pattern but somehow ignored this area in the continuing system of postgraduate course content. Discussions will have to go on in this matter to emulate national consensus through constant dialogues to have an inclusive complementary system for India by interactive joint venture between IMC and AYUSH bridging the gap by PCI assigning a role for Clinical Pharmacognosist. The National Commission for Human Resources in Health (NCHRH) includes Medical Council of India (MCI), Dental Council of India(DCI), Nursing Council of India(NCI) and Pharmacy Council of India (PCI); but does not consider Central Council of Indian Medicine(CCIM) and Central Council of Homeopathy in its sphere of activity.

Along with Modern allopathic system an inclusive health care pattern has to emerge as national therapeutic module with an intellectual stamp of Indian brand name on it. In order to achieve this end, organizations like CCIM and AYUSH cannot be alienated from the main stream of NCHRS. The role of clinical Pharmacognosist comes in to prominence in a more socially oriented and productive way to bridge the gap between the two main streams of therapies that exist. The discussions that go on the status and usefulness of Pharm.D would subside and Indian module would emerge distinctive before the international community. When we accredit a course seeing the need of Indian people and available resources in forefront, it should bear a national signature on it. Naturally the techniques and processes become branded and attract medical tourism to experience the Indian therapy in a more effective way generating new opportunity rather than wasting at the door steps of other countries for accreditation of a course.

\section{Conceptual difference between Modern medicine \& Indian ethnic Traditional medicine ${ }^{1,2}$}

A brief review of the conceptual difference in approach of Modern medicine and Indian Traditional ethnic variations would be of interest here to bring out the need of preserving Traditional therapy inclusive with modern medicine in this country. The modern medicine is not an off-shoot of Greek medicine and evolved in the middle of the $19^{\text {th }}$ century in Europe. The "unanipathy" propagated by Greek Physician Galen was popular in the pre-Islamic era in the region of Euphrates, Tigris and Nile culture. This became popular as "Unani" in the Islamic era and because of its holistic idiom came to India during the Mughal period and got well ingrained to Indian system by interacting with Ayurveda in the court of Humayoon and Akbar. The Arabian Physician Avicenna's Canon of medicine (Kitab Al-shifa) was popular in Europe and followed as a text book until the $17^{\text {th }}$ century later on developing to holistic Apothecary concept. The modern medicine started shaping only with the follow up of Industrial revolution in Europe. It was a spring board for a giant scientific leap giving an impetus in the field of medicine to molecule isolation from medicinal plants which later motivated to synthesis and SAR studies. 
This was a revolutionary change in the chemical history to lay foundation to Pharmacology based therapeutic index to bring out more and more hither to unknown molecules in to therapy on anti-disease basis. The net result was sidelining the practice of holistic indigenous traditional therapy existent in any part of the globe probably except in China.

In India also this gave an impetus to overlook the traditional techniques and processes used with regional variations to an extent and the practitioners in traditional field wanted to identify their products in parity with modern medicine by experimenting on bulk manufacture. Even the author had an experience of being approached by a prominent Ayurvedic establishment at a time in ' 70 s to convert their bulky formulations like Kashaya, ghrita etc to the modern compact formulations. Any holistic regional practice especially taking example of Ayurveda, there is no Indian road map of fixed process and formulations that exist. Each individual patient is considered as an institution by itself and considered different from another in physical, mental and spiritual status.

The Ayurveda and its samhitas merely serve as subtexts known as margi- a path finder to assess a person or the person's ethnic surroundings. The real modus operandi lies in the regional variations known as desi sampradaya attributed to available resources and techniques. For the very reason, the flexibility that is exercised from Kashmir to Kerala or Sourastra to Bengal fluctuates so much and the grandeur of uniformity (margi) in diversity (desi sampradaya) has to be preserved by an organization like AYUSH. The only uniformity in these diverse practices in contrast to the modern medicine is in its holistic (sakalya) vision on the patient's physical, mental and spiritual well being (as WHO has defined) - a way of living and more importantly to go in to exact root cause of ailment than symptomatic treatment. That raises the fundamental question as on how far bulk manufacture could be justified in such a holistic treatment. If samhitas or scriptures are reviewed there exist no fixed combinations and the decision for a recipe is arrived only after the proper diagnosis on a particular subject. The only general preparations which could claim trend setting are cosmetics preparations and so called "nutraceuticals". Remember the cognizance of Ayurveda is that all those found green are nothing but medicinal. At present, even an adaptogenic formulation like Chyavanaprasa for example contain about 45 and odd natural herbals sometimes with potassium sorbate to preserve through shelf life. Myth says the paste is prescribed by Aswins (one among three therapies) to Chyavana to regain his youth. The product right now claims by different manufacturers from consumer item to biomedical provider to traditional Ayurvedic product. ${ }^{(3)}$ It is observed the consistency and the taste vary from one manufacture to another and even observed within different batches. I should also add my childhood experience of seeing the very same paste being made at home with a local Vaidya for elders and children separately with different combinations. But the fact of the matter is that when this is prescribed by a true Traditional Practitioner some basic ingredients like amla are kept intact with addition or deletion of herbals suitable for a particular Patient as part that constitutes the course of treatment.

The standardization of raw materials and the end products is to be done meticulously under the supervision of the Traditional Practitioner where the clinical role of a Pharmacognosist can be redefined and justified according to basic idiom. But the momentum the Indian holistic systems take towards bulk manufacture is contrary to its basic principle and no one would be able to either enforce uniformity in standards or attribute Patient specificity for such market products. 
The section 33 in Indian Drugs \& Cosmetics Act permit Ayurveda/Traditional Physicians to prepare medicines required for their own patients.

At the very same time, there is a supreme court of India order prohibiting to prescribe Traditional products by physicians other than those who practice Traditional medicine. Certain preparations which came to prominence during post-Budha periods of Nagarjuna's Nalanda-Takshila era like herbo-mineal "Bhasmas' made meticulously by special process of incineration is under criticism by organizations like JAMA. There is a process of detoxification that takes place either by the herbo additives or chemical change to innocuous derivatives during the process and such preparations were used as substitutes to many surgical cases at that point of time. These bhasmas are subjected to $R \& D$ in various centers ${ }^{4,5}$ like IIT, Ayurvedic institutes and number of authentic papers are published to prove the effect of these products to nano sized particle, a technology being developed in west. The only difference here is that the science follows the experience. We are passing through a time where the "effect based" treatment details on patients should be scientifically analysed and documented as patient related experience and make the process details available through a single window. That is where the AYUSH expertise must come in par with MCI and use PCI to be supportive (through Clinical Pharmacognosist) to make a new concept of National health care policy.

There is an optimism before us if NCHRS takes the initiative to entrust AYUSH to identify ethnic Practitioners of different regions who do not have the manufacturing interests and assign such Practitioners to work in the same environment of modern medicine with Clinical Pharmacognosist to interact between two systems; many unaccounted clinical benefits around the country could be documented patient-wise by a single window system. The genuineness of such a program would be possible only when all the mandatory councils are prepared for a joint venture and Pharm.D syllabus need to be modified according to the national need. Surprisingly, many modern hospitals especially in south India maintain a holistic wing meant for Yoga and physiotherapy; but the clinical results are not exchanged.

When I tried to contact and exchanged the idea with many private hospitals, many modern physicians showed their inclinations to refer patients who are beyond their scheme of treatment provided there is no ethical problems arise. With the willingness of such patients, if they are referred to an ethnic Traditional Practitioner, Clinical Pharmacognosists have a great role in properly documenting each phase of the course of treatment and bring the experience through a single window. This will become complementary and inclusive to bring out region-wise variations in India through a single outlet to preserve our national wealth intact. So far, the beauty of diversified traditional practice of Ayurveda, Sidha, Unani, Naturopathy and secretive tribal wealth were so scattered making it difficult for any single foreign agency to pirate them. Let us hope we have a strong central agency to make a policy to combine the activities of mandatory bodies to evolve an inclusive National Therapeutic Module. 


\section{REFERENCES}

1. P.Velayudha Panicker .The uniqueness of Indian Clinical Pharmacognosist in Additive to the Role of Structural Phytochemistry- A review. Boletin Latinoamericano y del Caribe de Plantas Medicinales y Aromaticas 2012; 11(2): p.440-441

2. P.Velayudha Panicker The status of Indian Ethnic Therapies in National Scenario- A review. International J. of Phytotherapy Research 2013 ; Vol.3(2): 2013 p.1-5

3. Anil Kumar, Puneet Rinwa and Preetinder Kaur. Chyawanprash-A wonder Indian Rasayana from Ayurveda to modern age. Critical review in Pharmaceutical Sciences 2012; Vol.1 (2):1-8.

4. Tridib Kumar Bhowmick, Akkihebbal K. Suresh, Shantaram G. Kane, Ajit C. Joshi, Jayesh R. Bellare. Physicochemical characterization of an Indian traditional medicine, Jasada Bhasma: detection of nanoparticles containing non-stoichiometric zinc oxide. Journal of Nanoparticle Research April 2009; Volume 11(3):655-664.

5. Sudhaldev Mohapatra and C.B.Jha.Physicochemical characterization of Ayurvedic Bhasma (Swarna makshika Bhasma) an approach to standardization. International J of Ayurveda research 2010; April-June 1 (2): 82-86.

P.Velayudha Panicker.An inclusive Indian national therapy. Hygeia.J.D.Med 2014; 6(1):122-126. Available from http://www.hygeiajournal.com / Article ID- Hygeia.J.D.Med/129/14. D.O.I: 10.15254/H.J.D.Med.6.2014.129. 